\title{
Prototype Compressed Air Vehicle: An alternative to meet energy demand mitigation for sustainable development
}

\author{
Manoj Verma ${ }^{1}$, Gulshan Zameer Shah ${ }^{2}$ \\ ${ }^{1}$ Assistant Professor, Chhattisgarh Swami Vivekanand Technical University, Bhilai, Chhattisgarh-491107, India \\ ${ }^{2}$ Assistant Manager, NMDC Ltd., Kirandul, Dantewada, Chhattisgarh \\ E-mail address: manojverma.csvtu@gmail.com
}

Received July 1, 2019; received in revised form July 29, 2019; Accepted July 29, 2019; Available online July 2019

\begin{abstract}
The urgent need of eco-friendly transport vehicles and alternate source of energy other than fossil fuels draw attention of entire world towards the sustainable development of green technologies due to sudden climate changes and global warming. In the face of this climate crisis, Fossil fuel dependence, and volatile gasoline prices, it becomes imperative to explore possible opportunities in unconventional alternative-fuel vehicles. In this due course, Compressed Air Vehicles (CAV) is a thrust area of research. CAV utilizes high Kinetic energy of compressed air from compressor which is converted into mechanical work. To achieve the same, Compressed air is stored in a cylinder and released by a nozzle connected through the piping. High Velocity air passing through nozzle strikes the blade with a very high velocity, resulting in the rotation of prime mover. To produce a high torque and to reduce the rpm, the driving shaft is coupled with a compound gear train which is further connected with the axle, So that, rotational energy of prime mover is converted into mechanical work output easily and efficiently i.e. the motion of CAV. Based on this protocol a prototype compressed air vehicle was designed and developed. The efficiency of the prototype model under the different condition of load and speed in rpm was studied. Results show that although the CAV is a bold, unconventional solution for today's transportation challenges, it is ultimately less efficient, and compares poorly with gasoline and electric vehicles in all environmental and economic metrics.
\end{abstract}

Keywords: Sustainable development, green technology, compressed air vehicle

\section{Introduction}

\subsection{Compressed air vehicle milestones}

The first compressed air vehicle was built by Andraud and Tessie du Motay in Paris between 1838 and 1840 [1]. Since then the idea has been tried again and again, but has never reached commercialization. In recent years the French developer MDI has demonstrated advanced compressed air vehicles (CAV) [2,3]. However of his claims, the performance of CAV has been questioned by car manufacturers and automobile experts. Compressed air has been also used since $19^{\text {th }}$ century in power mines, locomotives and was previously the basis of naval torpedo propulsion [4,5].

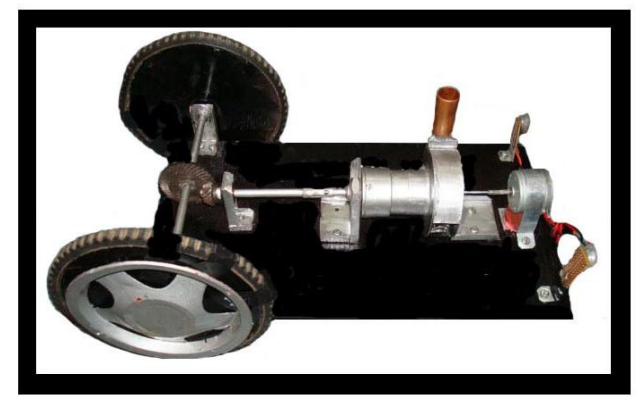

Figure 1 Compressed Air Vehicle Prototype Model 
In 1903, the Liquid Air Company of England manufactured a number of compressed air and liquefied air cars. The major problem with these cars and all compressed air cars (CAV) is the lack of torque produced by the "engines" and the cost of compressing the air [6,7].

\subsection{About Compressed Air Vehicle}

Compressed air vehicles are driven by the utilization of high pressure compressed air, which is either stored in a tank or can be obtained directly by the aid of the compressor $[8,9]$. Prototype vehicle consists of several suitable arrangements which converts highly pressurized compressed air into mechanical work i.e. the driving motion of wheels of the vehicle. Utilization of compressed air in prototype model can be utilized in two following ways :-

1. Firstly, compressed air vehicle uses compressed air to run its main driving gear shaft. By the virtue of rotational energy of shaft, the compressed air is converted into mechanical energy (motion of wheels of vehicle).

2. Secondly, Compressed air can also be utilized for small amount of power generation within the system providing scope for Auto-Electrical.

\subsection{Principle of CAV}

The working of Compressed Air Vehicle (CAV) is based on Newton's Second Law of motion i.e. "The rate of change of momentum of an object is directly proportional to the resultant force applied and is in the direction of the resultant force. The resultant force is equal to the rate of change of momentum." $[3,10]$ Here, the rate of change of momentum is caused in the air by allowing a high velocity jet of air to strike the blades of the driving wheel, and this high velocity air imparts a force to the blade. If the blades are free, it will rotate in the direction of applied force. In other words, the motive power of driving shaft is obtained by the rate of change in momentum of a high velocity jet of compressed air impinging on the blades of main driving shaft which is free to rotate, and this rotational energy of prime mover is further converted into mechanical work which leads to the motion of CAV.

\subsection{Mechanism of CAV}

Operation of Compressed Air Vehicle is entirely different from any other vehicle working with petrol/diesel or electricity. In conventional fuel vehicles, fuel is burnt inside the cylinder for the completion of four strokes but in compressed air vehicles are completely depends upon the dynamic action of air. It does not require any fuel rather than air. When compressed air strikes the blades of a prime mover through a nozzle it rotates and this rotational energy of the prime mover is further utilized to run a vehicle [11,12].

Main Driving shaft is equipped with compound gear train as Gear Box so that high rpm of the shaft can be reduced to produce sufficient torque. Output gear of the gear train is attached to a bevel gear. Bevel gears are used for the perpendicular intersecting shafts so that the power is then transmitted to the rear axle of the vehicle on which wheels are mounted. Wheels \& Bevel Gear is placed over ball bearings that ensures free rotation leading to the motion of CAV [13].

\subsection{Literature Survey}

One cannot accurately claim that compressed air as energy and locomotion vector is recent technology. At the end of the 19th century, the 
first approximations to what could one day become a compressed air driven vehicle already existed, with the arrival of the first pneumatic locomotives. In fact, two centuries before that Dennis Papin apparently came up with the idea of using compressed air (Royal Society London, 1687). In 1872 the Mekarski air engine was used for street transit, consisting of a single stage engine. It represented an extremely important advance in terms of pneumatic engines, due to its forward thinking use of thermodynamics, which ensured that the air was heated, by passing it through tanks of boiling water, which also increased its range between fill-ups. Numerous locomotives were manufactured and a number of regular lines were opened up (the first in Nantes in 1879)[3,13].

In 1892, Robert Hardie introduced a new method of heating that at the same time served to increase the range of the engine. However, the first urban transport locomotive was not introduced until 1898, by Hoadley and Knight, and was based on the principle that the longer the air is kept in the engine the more heat it absorbs and the greater its range. As a result they introduced a two-stage engine. Charles B. Hodges will always be remembered as the true father of the compressed air concept applied to cars, being the first person, not only to invent a car driven by a compressed air engine but also to have considerable commercial success with it. The H.K. Porter Company of Pittsburgh sold hundreds of these vehicles to the mining industry in the eastern United States, due to the safety that this method of propulsion represented for the 2 mining sector. Later on, in 1912, the American's method was improved by Europeans, adding a further expansion stage to the engine [5,13].

\subsection{Procedure for Making Prototype CAV Steps involved in development of a priority: -}

\section{Parts to be assembled: -}

1. A plywood frame of $32 \times 18 \mathrm{~cm}$.

2. A rear axle of $6 \mathrm{~mm}$ diameter having $\mathbf{1 7 . 5}$ cm length.

3. A shaft of dia. $6 \mathrm{~mm}$ and length $11 \mathrm{~cm}$.

4. A shaft of $2 \mathrm{~mm}$ diameter having $9 \mathrm{~cm}$ length.

5. A dynamo of $12 \mathrm{~V}$.

6. A Main driving shaft of diameter $6 \mathrm{~cm}$ having 30 blades.

7. Two bevel gears.

8. 4 ball bearings.

9. Two rear wheels of diameter $13 \mathrm{~cm}$.

10. A front guide wheel of $4 \mathrm{~cm}$ dia.

11. A compound gear train used as gearbox.

12. Nozzle of diameter $1.4 \mathrm{~cm}$.

13. Two led bulbs for headlights.

14. 10 screws and 2 washers for fitting.

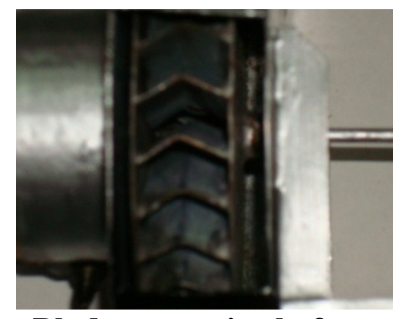

Blades on main shaft

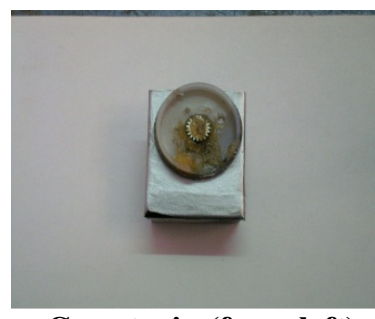

Gear train (from left)

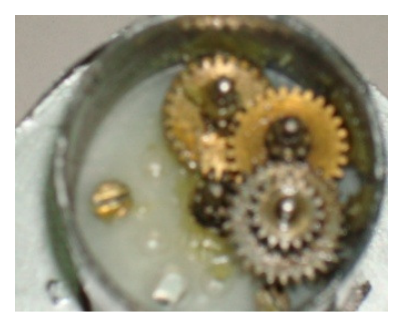

Gear train (from right)

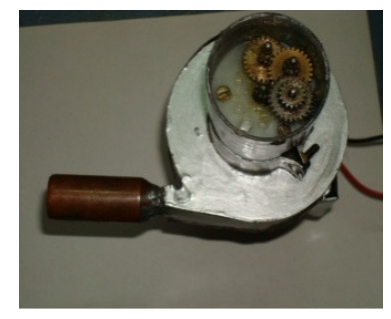

Converging nozzle with gear train 


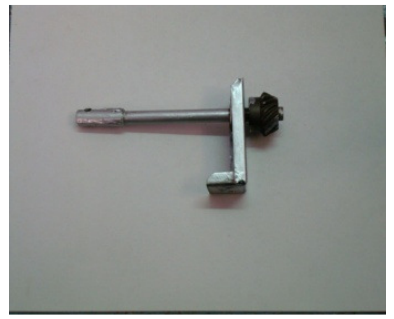

Shaft with bevel gear

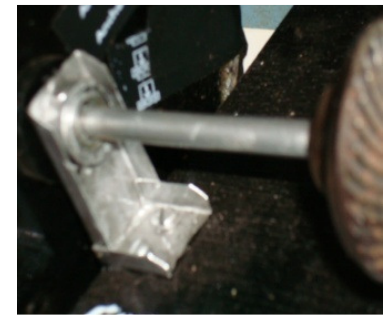

Bearings

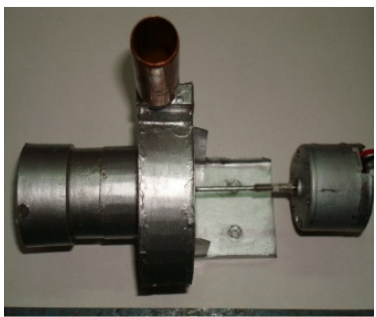

Top view with dynamo

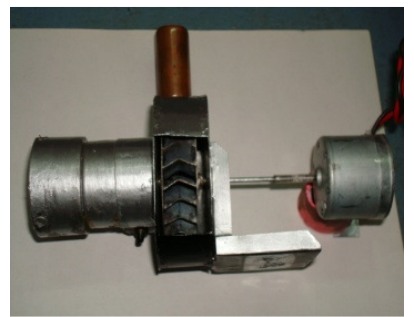

Bottom view

\subsection{Assembly Procedure}

- On the rear axle, one bevel gear was mounted over a ball bearing and this axle is installed with two wheels on two ball bearings to ensure free rotation, with the help of clamp.

- Front wheel of $4 \mathrm{~cm}$ diameter was fitted on the ply board having 10 no. of holes with the help of clamp.

- Main Driving shaft is provided with 30 blades is made by welding the two-circular plate around these 30 blades, these blades have a length of $3 \mathrm{~cm}$ and width of $1.4 \mathrm{~cm}$. Prime mover is coupled to a shaft of $2 \mathrm{~mm}$ diameter having $9 \mathrm{~cm}$ length.

- $2 \mathrm{~mm}$ width spiral casing was provided over the blade shaft which is also coupled with the shaft. Spiral casing is provided to direct the flow of air over the blades. Due to the Spiral shape casing a whirl is created in fluid

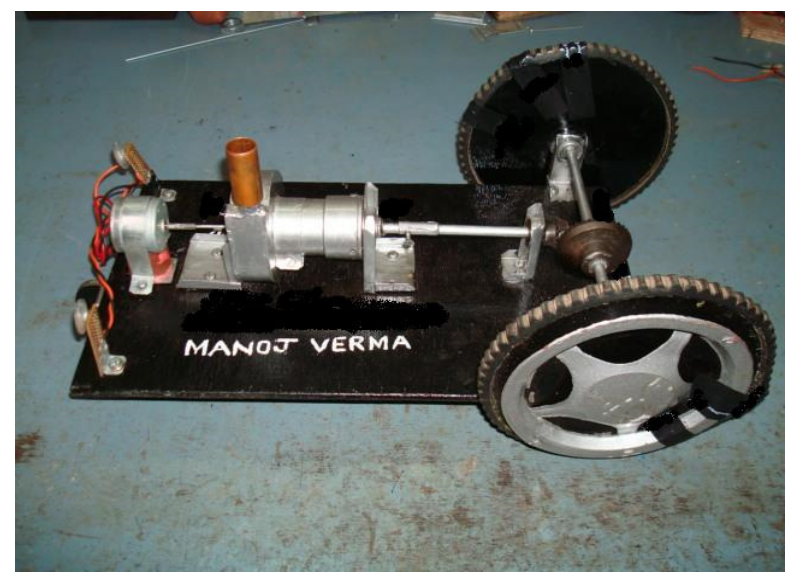

Figure 2 Left view (CAV) flow, which helps air to impart its Kinetic energy to the blades in a better way.

- At the upper end of spiral casing a convergent nozzle made up of bronze was fitted by means of bronze welding and the mouth of the nozzle is directed towards the blade. So that high velocity of air through the nozzle can be tangentially impinged over the blades.

- Driving Shaft is equipped with a compound gear train as Gear Box so that sufficient torque \& appropriate RPM can be obtained.

- The output gear of gear train is coupled with a shaft of $6 \mathrm{~mm}$ diameter and length $11 \mathrm{~cm}$ to obtain necessary torque which is fitted with a bevel gear at the other end. This shaft was supported by means of two clamps and screwed with the wooden base.

- This makes the arrangement for the driving of compressed air vehicle.

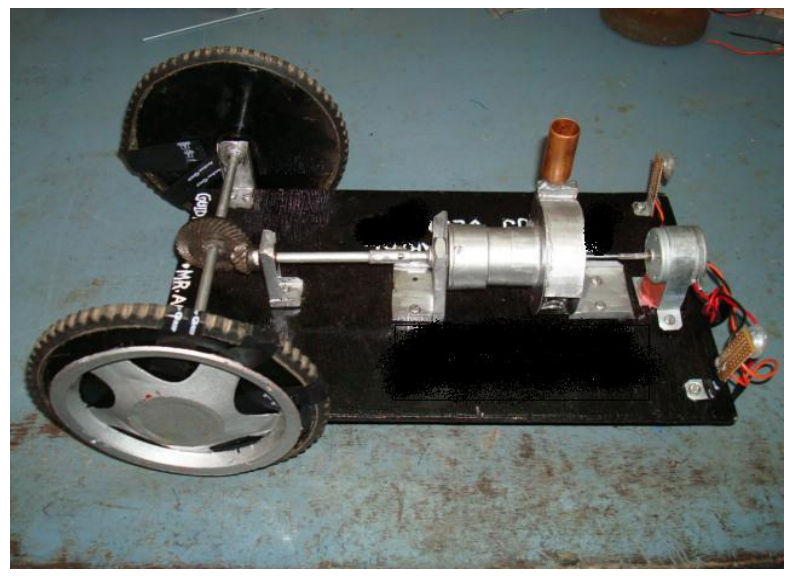

Figure 3 Right view (CAV)

66 CSVTU Research Journal on Engineering and Technology. 2019, Vol.8, No. 1 


\subsection{Power Generation Circuit}

- The extended part of main driving shaft is then coupled to a dynamo.

- This dynamo was supported by means of another clamp rounded at upper end and screwed at bottom end to the wooden base. A wedge is provided between dynamo and base for its proper alignment.

- The dynamo is connected to two LED bulbs by means of wiring and this bulb is then soldered on board, which is fitted on the wooden base with the help of clamps.

\subsection{Result and Discussion}

Prototype model constructed was tested under different conditions of load, friction, compressed air pressure and speed (rpm). The efficiency of CAV model was good and reliable (Table 1). We can expect that this model may bear load of $8 \mathrm{~kg}$ easily. The close observation of efficiency testing reveals that on increase in load and friction the speed of wheels and main driving shaft reduces (as shown in Figure 4).

\section{From the study of CAV, it was found that}

The principal advantages of an air powered vehicle are:

1. Refueling can be done at home using an air compressor or at service stations. The energy required for compressing air is produced at large centralized plants, making it less costly and more effective to manage carbon emissions than from individual vehicles.

2. Compressed air engines reduce the cost of vehicle production by about $20 \%$, because there is no need for a cooling system, Pumps, spark plugs, transmission, starter motor, mufflers etc

3. Compressed-air vehicles emit no pollutants.

4. Air turbines, closely related to steam turbines, is a technology over 50 years old. It is simple to achieve with low tech materials. This would mean that developing countries, and rapidly growing countries like China and India, could easily implement a less polluting means of personal transportation than an internal combustion engine automobile.

5. Lighter vehicles would result in less wear on roads.

6. The price of fueling air powered vehicles may be significantly cheaper than current fuels.

7. Reduction or elimination of hazardous chemicals such as gasoline or battery acid/metals

Table 1 Efficiency of CAV model in rpm under different conditions of load, friction and pressure

\begin{tabular}{|c|c|c|c|c|c|c|c|c|}
\hline \multirow{2}{*}{$\begin{array}{c}\text { S. } \\
\text { No }\end{array}$} & \multirow{2}{*}{$\begin{array}{c}\text { Speed of } \\
\text { CAV } \\
\text { model }\end{array}$} & \multirow{2}{*}{$\begin{array}{l}\text { Pres } \\
\text { sure } \\
(\mathrm{kg} / \\
\left.\mathrm{cm}^{2}\right)\end{array}$} & \multirow{2}{*}{$\begin{array}{l}\text { W/o } \mathrm{L} \\
\text { and } \mathrm{F}\end{array}$} & \multirow{2}{*}{$\begin{array}{c}\text { W/o L } \\
\& \\
\text { with } \\
\text { F }\end{array}$} & \multicolumn{4}{|c|}{ Loads (in kg) } \\
\hline & & & & & 2 & 4 & 6 & 8 \\
\hline \multirow{2}{*}{1.} & \multirow{2}{*}{$\begin{array}{l}\text { Rotation } \\
\text { of main } \\
\text { shaft (in } \\
\text { rpm) }\end{array}$} & 2.5 & 2328 & 2120 & 1650 & 1230 & 840 & 448 \\
\hline & & 5 & 3200 & 2935 & 2525 & 2130 & 1410 & 730 \\
\hline \multirow{2}{*}{2.} & \multirow{2}{*}{$\begin{array}{l}\text { Rotation } \\
\text { of wheel } \\
\text { (in rpm) }\end{array}$} & 2.5 & 933 & 850 & 660 & 492 & 336 & 253 \\
\hline & & 5 & 1280 & 1164 & 1010 & 852 & 564 & 364 \\
\hline
\end{tabular}




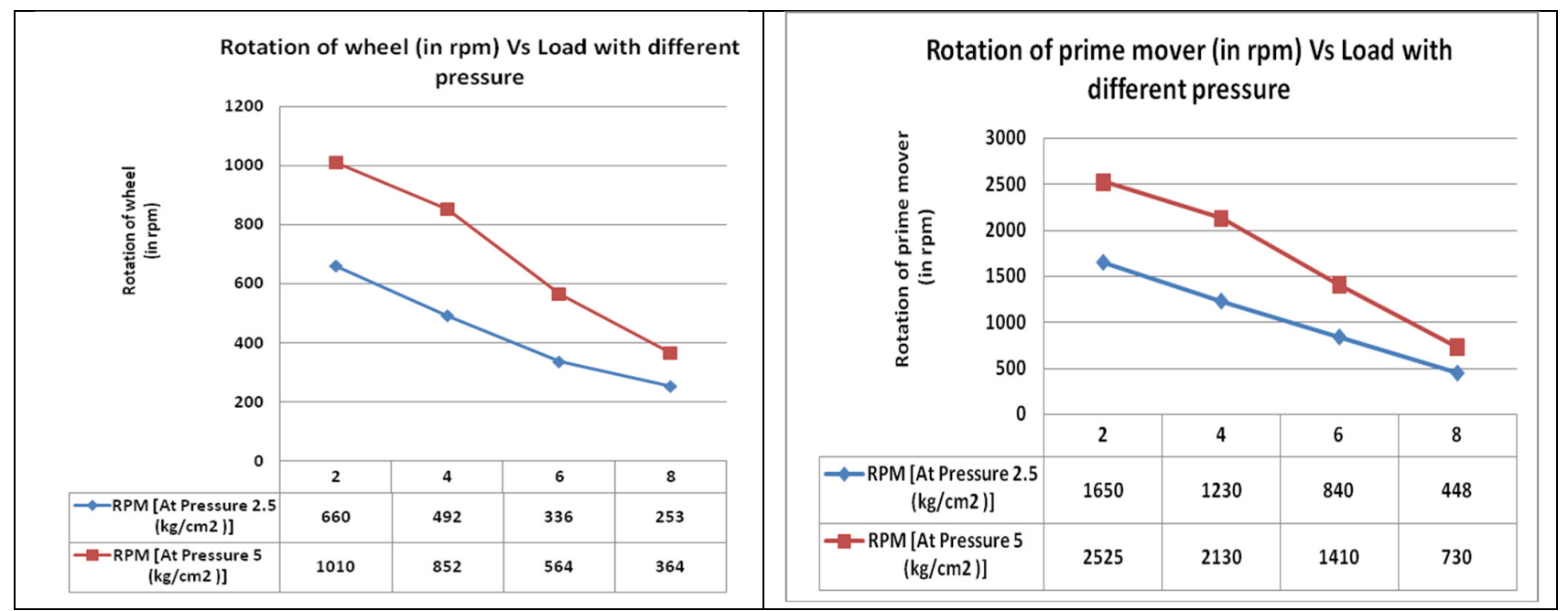

Figure 4 Experimental Results

\section{Drawbacks:-}

1. Since the present CAV get its air from an air compressor whose operation requires electrical energy, hence it is not complete green technology.

2. Requirement of air compressor is essential.

3. May not be a suitable for continuous long run, as the reservoir of air has to be maintained.

\section{Conclusion}

The $24^{\text {th }}$ Conference of Parties (COP-2018) in Katowice, Polan centered towards the renewable energy scenario in the world. In this paradigm India has already bound to the emission of GHG and restricts use of their fossil fuels, even though it restricts, its social and economical developments. Therefore, development of the Compressed air vehicles may be a good line of action. Our developed prototype CAV model works appropriately for transport of low load up to $6 \mathrm{~kg}$ with good speed. The future planning includes the design and development of CAV with heavy load bearing capacity with appropriate speed.
However, the cost of the compressing air is a critical issue and it is under consideration.

\subsection{Scope of Further Work}

1. In CAV currently compressed air is supplied by means of an air compressor which can also be supplied by compressed air in air cylinder.

2. Load carrying capacity of the CAV can be improved by using the metallic frame, as base instead of plywood base.

3. Acceleration/Deceleration system can be provided by regulating the valve through which air or made to flow

4. Braking system can be provided on the wheels

5. Reversing of the vehicle can be done by changing the direction of blades \& shaft. 


\section{REFERENCES}

[1] A. Papson, F. Creutzig, and L. Schipper, “ Compressed air vehicles: Drive-cycle analysis of vehicle performance, environmental impacts, and economic costs," Transp. Res. Rec. 2191, 67-74 (2010).

[2] H. Daneshi and A. K. Srivastava, “ Security-constrained unit commitment with wind generation and compressed air energy storage," IET Gener. Transm. Distrib. 6(2), 167-175 (2012).

[3] S. S. Verma, " Air powered vehicles," Open Energy Fuels J. 1, 54-56 (2008).

[4] S. Park, Y. Kim, and N. Chang, " Hybrid energy storage systems and battery management for electric vehicles," in Proceedings of the 50th ACM/EDAC/IEEE Design Automation Conference (DAC) (IEEE, 2013)

[5] G. Negre, “ Compressed-air or gas and/or additional-energy engine having an active expansion chamber," U.S. patent US20100051003 A1 (4 March 2010).

[6] Car runs on compressed air, but will it sell?". Associated Press. http://www.msnbc.msn.com/id/6138972/. Retrieved 2008-09-12.

[7] Advantages of compressed air as an energy vector".theaircar.com.http://www.theaircar. com/acf/air-cars/energy-storage.html.

[8] Newton's "Axioms or Laws of Motion" can be found in the "Principia", http://en.wikipedia.org/wiki/Mathematical_ Principles_of_Natural_Philosophy

[9] Gizmag Team, "French auto runs on compressed air technology", http://www.gizmag.com/go/3523/

69 CSVTU Research Journal on Engineering and Technology. 2019, Vol.8, No. 1
[10]Dr. S.S. Thipse, SAE 1999-01-0623, Schechter. M., Special Feature: Air Pollution Control Technologies "New Cycles for Automobile engines.2008"

[11] Internet website, www.mdi.lu Internet websitehttp://www.inhabitat.com/2007/06/ 01/tata-motors-air-car.

[12] Bureau of Energy Efficiency "Compressed air system”, www.bee-india.nic.in.

[13] Sengupta, D. Tata Motors to Roll Out Car That Runs on Compressed Air Instead of Fuel. The Economic Times, March 22, 2008. 